\title{
Preparation and Characterization of Reduced Graphene-P3HT Composite Thin Films for Use as Transparent Conducting Electrodes
}

\author{
Lam Minh Long1, Dang Dinh Long1, Nguyen Phuong Hoai Nam¹, Nguyen Trong Tinh ${ }^{2}$, \\ Sergei Antonovic Chizhik ${ }^{3}$, Nguyen Nang Dinh ${ }^{1}$ \\ ${ }^{1}$ University of Engineering and Technology, VNU in Hanoi, Hanoi, Vietnam \\ ${ }^{2}$ Institute of Applied Physics and Scientific Instrument, Vietnamese Academy of Science and Technology, Hanoi, Vietnam \\ ${ }^{3}$ A.V. Luikov Heat and Mass Transfer Institute, National Academy of Sciences of Belarus, Minsk, Belarus \\ Email:dinhnn@vnu.edu.vn
}

How to cite this paper: Long, L.M., Long, D.D., Nam, N.P.H., Tinh, N.T., Chizhik, S.A. and Dinh, N.N. (2018) Preparation and Characterization of Reduced GrapheneP3HT Composite Thin Films for Use as Transparent Conducting Electrodes. Materials Sciences and Applications, 9, 464-472. https://doi.org/10.4236/msa.2018.95032

Received: April 4, 2018

Accepted: May 18, 2018

Published: May 22, 2018

Copyright $\odot 2018$ by authors and Scientific Research Publishing Inc. This work is licensed under the Creative Commons Attribution International License (CC BY 4.0).

http://creativecommons.org/licenses/by/4.0/

(c) (i) Open Access

\begin{abstract}
With the aim of producing simple and effective transparent conducting electrodes, the conducting polymer poly(3-hexylthiophene) (P3HT) incorporated with reduced graphene oxide film (rGO) (called rGO-P3HT) was prepared by spin-coating method. Structural, electrical and optical characterization showed that rGO-P3HT films 9.0 wt\% P3HT exhibited good stability when exposed to the ambient atmosphere. These composite films of $200 \mathrm{~nm}$ thickness possess a sheet resistance and transparency of $\mathrm{R}_{\square} \sim 17 \Omega$ and $\mathrm{T} \sim 72 \%$, respectively. Owing to containing conducting polymer, rGO-P3HT-coated glass could be efficiently used in photovoltaic applications, in organic solar cells in particular, with the replacement of the indium tin oxide (ITO) and fluorine tin oxide (FTO) electrodes.
\end{abstract}

\section{Keywords}

Composite rGO-P3HT Thin Films, Transparent Conducting Electrode, Sheet Resistance Transmittance

\section{Introduction}

Transparent conducting electrodes (TCEs) have received increasing interest due to their various technological applications such as electrochromic display (ECD) [1], touch screens, liquid crystal displays (LCDs), organic light emitting diodes (OLEDs) and organic solar cells (OSCs) [2] [3] [4]. At present, there are many kinds of TCEs made from inorganic transparent conducting oxides (TCO) such 
as flor-doped tin Oxide (FTO), Sn-doped indium oxide (ITO), aluminum-doped $\mathrm{ZnO}$ (AZO), etc. The $100 \mathrm{~nm}$-thick TCO films possess a high transparency up to $90 \%$ and a large conductivity of $1.2 \times 10^{6} \mathrm{~S} / \mathrm{cm}$ or low sheet resistance $\left(\mathrm{R}_{\square}-10 \Omega\right)$ [5]. However, TCO films have many disadvantages, for example, their compounds are expensive (specially In for ITO), sophisticated production technology like CVD, Dc- and Rf-sputtering, Electron beam deposition, etc. Nowadays graphene is considered a leading candidate to replace conventional TCO electrodes because of its high transparency and exceptional transport properties. The effect of chemical p-type doping on graphene stacks was studied in order to reduce the sheet resistance of graphene films to values approaching those of conventional transparent conducting oxides. The doping decreases the sheet resistance by a factor of 3 , yielding films comprising eight stacked layers with a sheet resistance of $90 \Omega$ at a transparency of $80 \%$ [6]. Reduced graphene oxide (rGO) can be considered as a p-type semiconductor [7]; the energy bandgap is in a range of from 1.9 to $3.6 \mathrm{eV}$ depending on the reduction level [8]. A simple and effective TCE based on reduced graphene oxide film embedded with silver nanowire-(AgNW-rGO) was developed [9]. The AgNW-rGO hybrid electrode was fabricated by using a simple and scalable dip-coating technique. This solution processed TCEs that showed high electrical conductivity in comparison with pristine AgNW. The electrical conductivity was found to increase in the number of dipping cycles of AgNW after coating the graphene oxide. This increase in the observed conductivity was attributed to the gas-barrier property of rGO. At room temperature AgNW/rGO films possess a sheet resistance of $27 \Omega$ and a transmittance of $72 \%$ (at $550 \mathrm{~nm}$ ) [9]. The TCEs of multiwall carbon nanotubes (MWCNTs) incorporated with graphene quantum dots were made for GaN-based light emitting diodes (LED). A sheet resistance of $533 \Omega$ and a transmittance of $88 \%$ were obtained when chemical-vapor-deposition grown graphene was fused across CNT networks [10]. Recently [11], we have prepared composite films of poly(3-hexylthiophene) and reduced graphene oxides (rGO-P3HT) for sensing ammonia gas. We recognized that rGO-P3HT films exhibited a rather large transparency and a reasonable sheet resistance. The fact that the films were thick and the sheet resistance was large is a requirement of $\mathrm{NH}_{3}$ gas conductivity sensors; consequently a large content of $\mathrm{P} 3 \mathrm{HT}$ was necessary to embed in the composite films. However, the conductivity and transparency can be improved by adjusting the compound ratio of $\mathrm{P} 3 \mathrm{HT} / \mathrm{rGO}$ in the composite materials in case the rGO-P3HT films are used for TCEs.

In this work we present new results obtained in the investigation on the optical and electrical properties of rGO-P3HT composite films made by a simple spin-coating technique and we would like to suggest a potential application of rGO-P3HT coatings for transparent conducting electrodes in organic solar cells.

\section{Experiment}

\subsection{Preparation of rGO Solution}

Preparation of rGO solutions was followed by the procedure described elsewhere 
[11]. Herein we emphasize changes in chemicals volumes, graphite flakes (GF) filled in $\mathrm{KMnO}_{4}$ and $\mathrm{HNO}_{3}$ as well as the content of $\mathrm{P} 3 \mathrm{HT}$ embedded in rGO. Spin conditions for depositing rGO-P3HT films were also modified to deposit films with a thickness that is suitable for use as TCEs.

Mixtures of $0.2 \mathrm{~g} \mathrm{GF}, 0.3 \mathrm{~g} \mathrm{NaNO}_{3}$ and $8.5 \mathrm{ml} \mathrm{H}_{2} \mathrm{SO}_{4}$ were put in a glass beaker, then $1.5 \mathrm{~g} \mathrm{KMnO}_{4}$ and $30 \mathrm{ml}$ of distilled water was poured into the glass beaker to get a liquid solution. Next, $12 \mathrm{ml} \mathrm{H}_{2} \mathrm{O}_{2}$ was added to this solution and ultrasonically stirred at room temperature for 10 hours to separate $\mathrm{MnO}_{4}{ }^{-}$and $\mathrm{MnO}_{2}$ into $\mathrm{Mn}^{+}$ions, yielding a solution with a bright-yellow color. The obtained solution was unmoved for 24 hours waiting for a paste-like layer (with dark-yellow color) deposited at the glass beaker bottom, constituting rGO paste. By slowly sucking, the liquid solution above the rGO paste was completely taken off the beaker. Finally, $18 \mathrm{mg}$ of $\mathrm{rGO}$ paste was diluted in $100 \mathrm{ml}$ of $\mathrm{N}, \mathrm{N}$-dimethylformamide (DMF) solvent in $200 \mathrm{ml}$-volume glass beaker and ultrasonically stirred for $30 \mathrm{~min}$ for completely dispersing $\mathrm{rGO}$ in DMF (rGO-DMF). After 24 hours waiting for the solution stabilization, $60 \mathrm{ml}$ of rGO-DMF solution from the glass beaker top was taken and kept in another beaker for further use.

\subsection{Preparation of $\mathrm{rGO}+\mathrm{P} 3 \mathrm{HT}$ Composite}

P3HT with purity of $\geq 99.9 \%$ were purchased from Sigma-Aldrich Corporation. P3HT powder with a volume of $6 \mathrm{mg}$ was mixed in $1.2 \mathrm{ml}$ of rGO-DMF solution. This solution was ultrasonically stirred for 2 hours at room temperature. For all the volumes of chemicals of P3HT and rGO, a content ratio of P3HT:rGO chosen was ranging from 3.0 to $12.0 \mathrm{wt} \%$. (Namely, the volume content of P3HT embedded in rGO matrix was 3, 5, 7, 9 and $12 \mathrm{wt} \%)$. Using spin-coating, rGO-P3HT solutions were deposited onto Corning-247 glass sheets of $10 \mathrm{~mm} \times$ $10 \mathrm{~mm}$ in size. The following experimental parameters were used for coating: a delay time of $100 \mathrm{~s}$, a rest time of $50 \mathrm{~s}$, a spin speed of $2000 \mathrm{rpm}$, an acceleration of $650 \mathrm{rpm}$, and finally a wating time of $3 \mathrm{~min}$. To dry the composite films, a flow of dried gaseous nitrogen was used for 8 hours. For a solidification avoiding the use of solvents, the film samples were annealed at $150^{\circ} \mathrm{C}$ for 3 hours in a "SPT-200" vacuum drier.

The thickness of the films was measured on a "Veeco Dektak 6M" stylus profilometer, all samples chosen for further investigation have thickness of $200 \mathrm{~nm}$. The electrical properties (sheet resistances) of composite samples were measured by four-point probe method. Atomic force microscope (AFM) images were obtained using a Belarusian "NT 206" atomic force microscope operating in a tunnel current mode.

Crystalline structure of the films was characterized by using D-5000 Siemens $\mathrm{X}$-ray diffractometer (XRD). Transmittance spectra were measured on JASCO V-570 spectrophotometer using using "baseline elimination" from the substrate (Corning-247 glass) absorption and the sheet resistance of the samples were 
measured on a "KEITHLEY 2602" system source meter using four-point probe measurements.

\section{Results and Discussion}

\subsection{Conducting Property of rGO-P3HT Films}

The results of four-point probe measurements showed that sheet the resistance $\left(\mathrm{R}_{\square}\right)$ of the rGO-P3HT was strongly dependent on the P3HT content (C) as shown in Figure 1. From the $\mathrm{R}_{\square}$ vs. $\mathrm{C}$ plot, it is seen that the optimum content of P3HT embedded in rGO is around $\mathrm{C}=9.0 \mathrm{wt} \%$, corresponding to $\mathrm{R}_{\square}$ of $17 \Omega$. Up to a few percent of P3HT ( $7 \mathrm{wt} \%$ ) the $\mathrm{R}_{\square}$ was found to be inversely proportional to P3HT content. This can be attributed to the enrichment of major charge carriers (namely holes) from p-type $\mathrm{P} 3 \mathrm{HT}$ organic semiconductor [12] to the rGO-P3HT composite film. Beyond 9 wt\% P3HT the $\mathrm{R}_{\square}$ increased slowly and started increasing fast from $10 \mathrm{wt} \%$. This may be explained due to 1) the saturation of the hole concentration, 2) the formation of numerous boundaries (or hetero-interfaces) of $\mathrm{P} 3 \mathrm{HT} / \mathrm{rGO}$, resulting in decrease of the mobility of the holes of both the rGO and $\mathrm{P} 3 \mathrm{HT}$ in the composite films.

Although the value of the sheet resistance of the composite film (i.e. $17 \Omega$ ) is still large in comparison with the one of the commercial ITO films (less than 10 $\Omega$ ), it is quite comparative to the sheet resistance of AgNW-rGO films made by dip-coating technique as reported in [9] and much lower than that of graphene electrode [6].

\subsection{Morphology, Structure and Transmittance of rGO-P3HT Films}

Figure 2 shows the AFM of an annealed rGO-P3HT composite film with a percentage of $\mathrm{C}=0.9 \mathrm{wt} \% \mathrm{P} 3 \mathrm{HT}$. From this figure one can see that the roughness of the rGO-P3HT film surface was estimated as about $1.50 \mathrm{~nm}$. This roughness enables increasing the interface contact between the rGO-P3HT (served as a TCE) and the other conducting polymer layer being deposited on the TCE for making devices.

A XRD pattern of a rGO-P3HT film is shown in Figure 3. In a $2 \theta$ range from 2 to 30 degrees two characteristic peaks are observed: the $2 \theta=5.5^{\circ}$ peak is consistent with the peak for $\mathrm{P} 3 \mathrm{HT}$ [13] and the $26.1^{\circ}$ peak belongs to $\mathrm{rGO}$ as reported in [14].

The full width at half maximum (FWHM) of these peaks is rather large. This shows that both the P3HT and rGO were formed in nanocrystalline particles. Using Scherrer formula, the calculated particles size $(\tau)$ can be found:

$$
\tau=\frac{0.9 \lambda}{\beta \times \cos \theta}
$$

where $\lambda$ is the wavelength of the X-ray used for incident radiation. In our experiment $\mathrm{Cu}$-tube was used, thus $\lambda=0.15406 \mathrm{~nm}, \beta$ the FWHM (in radians) and $\theta$ is the diffraction angle of the considered peak (namely Bragg angle) [15]. 


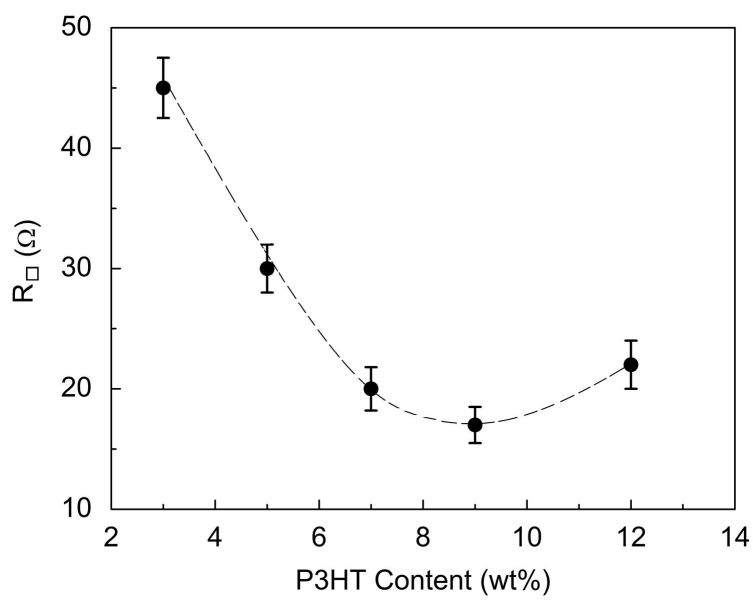

Figure 1. Sheet resistance of composite films vs. P3HT content. Film thickness $\mathrm{d}=200 \mathrm{~nm}$.

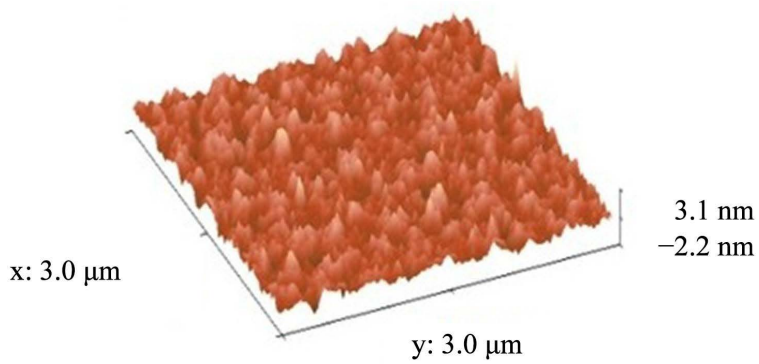

Figure 2. AFM of a rGO-P3HT film annealed at $120^{\circ} \mathrm{C}$ for 2 hours.

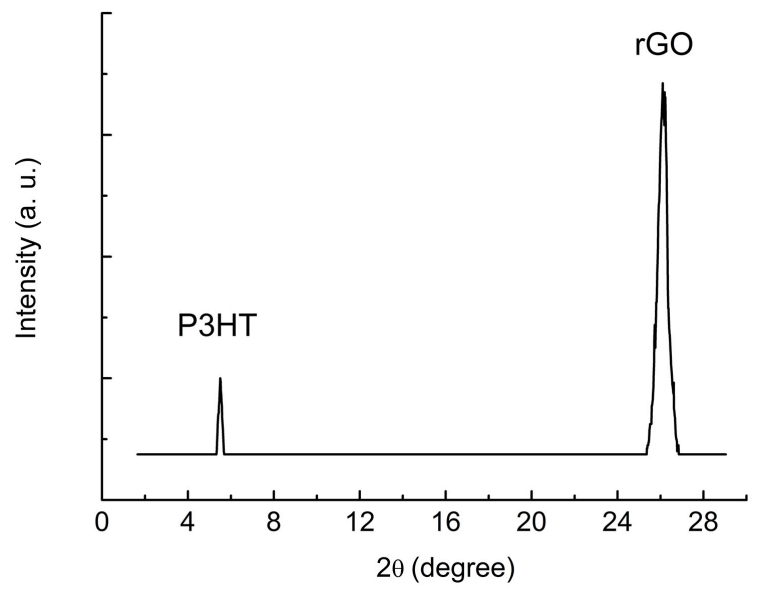

Figure 3. XRD of a rGO-P3HT film with thickness $d=$ $200 \mathrm{~nm}$.

From the XRD pattern in Figure 3 for the P3HT peak, $\beta=0.0021$ and $\tau$ was found to be of ca. $65 \mathrm{~nm}$. For the rGO peak, $\beta=0.0034$, consequently $\tau \approx 45 \mathrm{~nm}$.

The typical transmittance spectrum of the rGO-9.0 wt\% P3HT film is shown in Figure 4.

The largest transparency $(\sim 80 \%)$ is observed at $400 \mathrm{~nm}$, at $550 \mathrm{~nm}$ (the largest 
sensitivity of human eyes) it is about $72 \%$; and the optical absorption edge-at around ultra-violet wavelengths. This is due to the strong absorption of rGO at a range from 240 to $275 \mathrm{~nm}$ that caused by $\pi-\pi^{*}$ transition of aromatic C-C rings and $n-\pi^{*}$ of $\mathrm{C}-\mathrm{O}$ bond [16]. The P3HT strongly absorbed light in a range of wavelengths from 500 to $750 \mathrm{~nm}$ that concerned the $\pi-\pi^{*}$ bonding in the P3HT chain [17]. This is why the transmittance of the rGO-P3HT film decreased in this wavelength range (Figure 4).

In this work, we used the UV-Vis spectra data to estimate the energy bandgap $\left(\mathrm{E}_{\mathrm{g}}\right)$ of the composite film. For rGO combined with the conducting polymer (P3HT), $\mathrm{E}_{\mathrm{g}}$ is the gap between the highest occupied molecular orbitals (HOMO) and the lowest unoccupied molecular orbitals (LOMO). It can be determined by using the expression [18]:

$$
\alpha(v) h v=A\left(h v-E_{g}\right)^{n}
$$

where $h$ is Planck's constant, $v$ is the frequency of the incident UV-Vis radiation, $\mathrm{A}$ is a constant and $\mathrm{n}$ is $1 / 2$ for direct band semiconductors and 2 for indirect band gap semiconductors. In case the reflectance of the films is ignored, the frequency dependence of $\alpha(v)$ can be calculated from the experimental optical transmittance spectra $(T)$, using following relation [19]:

$$
\alpha(v)=\frac{1}{d} \ln \left(\frac{1}{T}\right)
$$

In our experiments, for the rGO-P3HT film the best fits were found for $\mathrm{n}=$ $1 / 2$ (corresponding to the direct band). The $h v$-dependence of $(\alpha h v)^{2}$ is plotted in Figure 5. From this figure one can see that a line segment AB exhibits the linear hv-dependence of $(\alpha h v)^{2}$. By extending $\mathrm{AB}$ to cross the abscissa, the value of $\mathrm{E}_{\mathrm{g}}$ of the rGO-P3HT film was found to be $3.46 \mathrm{eV}$ which is closed to the value reported in for $\mathrm{rGO}$ with an average reduction level [20].

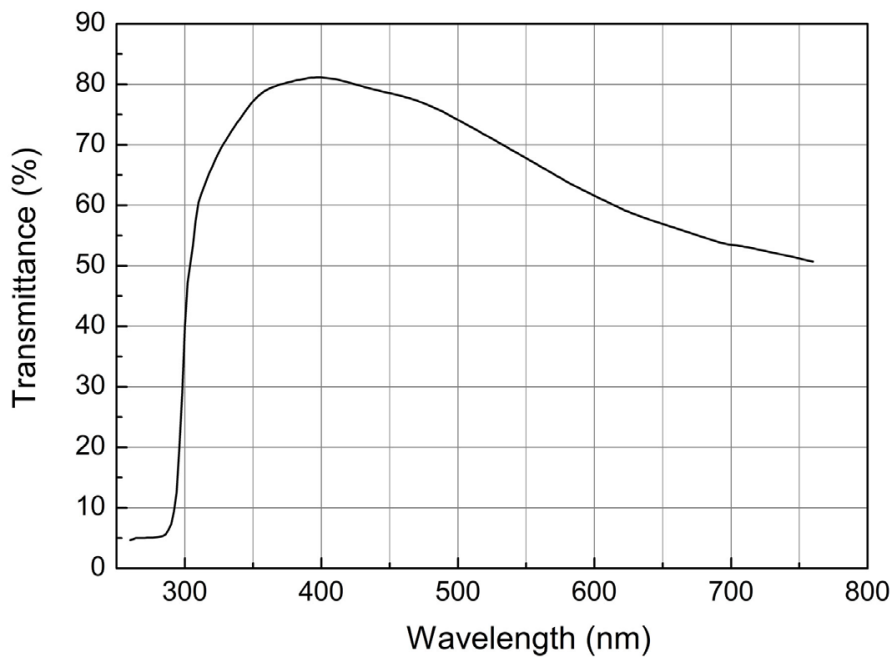

Figure 4. Transmittance of rGO-P3HT (9.0 wt\% P3HT) film with thickness of $200 \mathrm{~nm}$. 


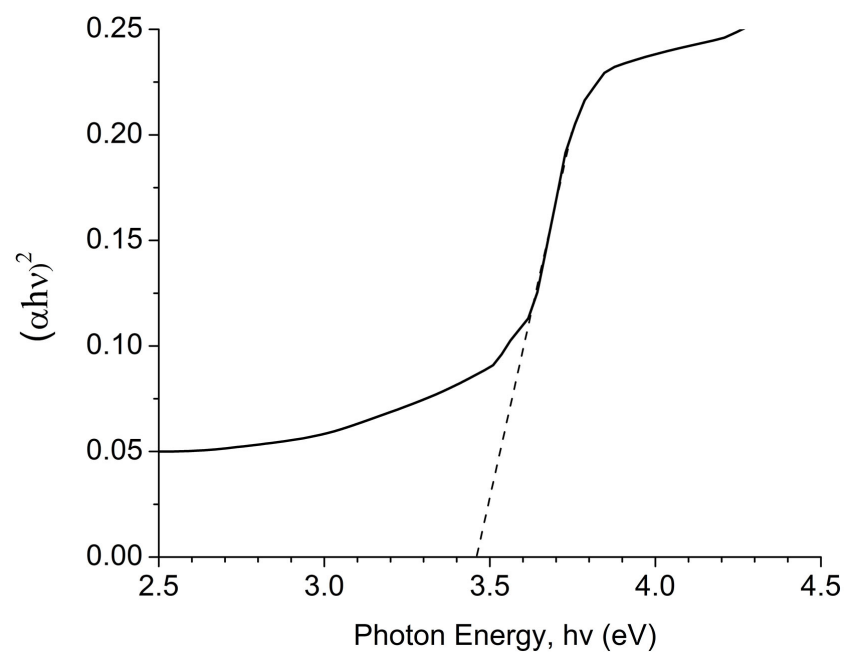

Figure 5. Plot of $(\alpha h v)^{2}$ vs. Photon energy $(h v)$ for the determination of Eg of rGO-P3HT film.

Two importance parameters of a TCE are transmittance (in visible range of wavelengths- $-\mathrm{T}$ ) and sheet/square resistance $\left(\mathrm{R}_{\sqsubset}\right)$. For our rGO-P3HT films, at room temperature and wavelength of $550 \mathrm{~nm}$ the sheet resistance and transparency of $\mathrm{R}_{\square} \sim 17 \Omega$ and $\mathrm{T} \sim 72 \%$ were obtained, respectively. Thus, for the 200 nm-thick composite film, the conductivity was found to be of $\sigma=3.0 \times 10^{5} \mathrm{~S} / \mathrm{m}$. With such a large conductivity and a high transmittance, rGO-P3HT-coated glass can be used as TCEs for optoelectronic devices like OLED and ECD. Especially for OSC, because rGO-P3HT films contain a conducting polymer (namely $\mathrm{P} 3 \mathrm{HT}$ ) which is commonly used as an efficiently photoactive layer in organic solar cells [21] [22] [23] [24].

\section{Conclusions}

A simple and effective transparent conducting electrodes (TCEs) based on reduced graphene oxide film embedded with conducting polymer P3HT (rGO-P3HT) was developed. The rGO-P3HT composite electrode was fabricated by using a simple spin-coating method. This solution processed TCEs showed small sheet resistance (large electrical conductivity). rGO-P3HT TCEs also exhibited good stability when exposed to the ambient atmosphere. The optimum concentration of P3HT embedded in rGO was found to be of $9.0 \mathrm{wt} \%$. The sheet resistance and transparency of the composite film attained a value of $\mathrm{R}_{\square} \sim 17 \Omega$ and $\mathrm{T} \sim 72 \%$, respectively.

Our results provide a possible way to replace the indium tin oxide (ITO) or fluorine tin oxide (FTO) with rGO-P3HT films in the spin-coating technique, and make it promising to produce composite films for future flexible photovoltaic applications.

\section{Acknowledgements}

One of the authors (L. M. Long) expresses his sincere thanks to University of 
Engineering and Technology (VNU Hanoi) for support during his Ph.D. student research.

\section{References}

[1] Granqvist, C.G. (1995) Handbook of Inorganic Electrochromic Materials. Elsevier, Amsterdam.

[2] Baldo, M.A., O’brien, D.F., You, Y., Shoustikov, A., Sibley, S., Thompson, M.E. and Forrest, S.R. (1998) Highly Efficient Phosphorescent Emission from Organic Electroluminescent Devices. Nature, 395, 151-154.

[3] Li, J., Hu, L., Wang, L., Zhou, Y., Grüner, G. and Marks, T.J. (2006) Organic Light-Emitting Diodes Having Carbon Nanotube Anodes. Nano Letters, 6, 2472-2477.

[4] Xu, W.-F., Chin, C.-C., Hung, D.-W. and Wei, P.-K. (2013) Transparent Electrode for Organic Solar Cells Using Multilayer Structures with Nanoporous Silver Film. Solar Energy Materials and Solar Cells, 118, 81-99.

[5] Stadler, A. (2012) Transparent Conducting Oxides-An Up-To-Date Overview. Materials, 5, 661-683

[6] Kasry, A., Kuroda, M.A., Martyna, G.J., Tulevski G.S. and Bol, A.A. (2010) Chemical Doping of Large-Area Stacked Graphene Films for Use as Transparent, Conducting Electrodes. ACS Nano, 4/7, 3839-3844. https://doi.org/10.1021/nn100508g

[7] Marashima, Y., Karim, M.R., Furue, R., Matsui, T., Takehira, H., Wakata, K., Toada, K., Ohtani, R., Nakamura, M. and Hayami, S. (2016) Reduced Graphene oxide-Transition Metal Hybrids as p-Type Semiconductors for Acetaldehyde Sensing. Inorganic Chemítry Frontiers, 3, 842-848. https://doi.org/10.1039/C6QI00058D

[8] Yaragalla, S., Rajendran, R., Jose, J., AlMaadeed, M.A., Kalarikkal, N. and Thomas, S. (2016) Preparation and Characterization of Green Graphene Using Grape Seed Extract for Bioapplications. Materials Science and Engineering C, 65, 345-353. https://doi.org/10.1016/j.msec.2016.04.050

[9] Meenakshi, P., Karthick, R., Selvaraj, M. and Ramu, S. (2014) Investigations on Reduced Graphene Oxide Film Embedded with Silver Nanowire as a Transparent Conducting Electrode. Solar Energy Materials \& Solar Cells, 128, 264-269. https://doi.org/10.1016/j.solmat.2014.05.013

[10] Kang, C.H. Shen, C., Saheed, M.S., Mohamed, N.M., Khee Ng, T.T., Ooi, B.S. and Burhanudin, Z.A. (2016) Carbon Nanotube-Graphene Composite Film as Transparent Conductive Electrode for GaN-Based Light-Emitting Diodes. Applied Physics Letters, 109, 081902. https://doi.org/10.1063/1.4961667

[11] Long, L.M., Thu, H. T., Trung, T.Q., Truong, V.-V. and Dinh N.N. (2018) Characterization of Structural and NH3 Gas Sensing Properties of P3HT+rGO+CNT Films Made by Spin-Coating. Journal of Nanomaterials (Submitted in March 8, 2018).

[12] Omer, B. M. (2013) Optical Properties of Poly (3-hexylthiophene-2,5-diyl) and Poly (3-hexylthiophene-2,5-diyl)/[6,6]-Phenyl C61-Butyric Acid 3-Ethylthiophene Ester Thin Films. Journal of Nano and Electronic Physics, 5, 03010 (4 p).

[13] Abu-Zahra, N. and Algazzar, M. (2013) Effect of Crystallinity on the Performance of P3HT/PC70BM/n-Dodecylthiol Polymer Solar Cells. Journal of Solar Energy Engineering, 136/2, 021023 (7 p).

[14] Stobinski, L., Lesiaka, B., Malolepszyc, A., Mazurkiewiczc, M. and Mierzwaa, B. (2014) Graphene Oxide and Reduced Graphene Oxide Studied by the XRD, TEM and Electron Spectroscopy Methods. Journal of Electron Spectroscopy and Related 
Phenomena, 195, 145-154. https://doi.org/10.1016/j.elspec.2014.07.003

[15] Cullity, B.D. (1978) Elements of X-Ray Diffraction. 2nd Edition, Addison-Wesley Publishing Company, Inc., Reading, 102.

[16] Vinoth, R., Babu, S.G., Bahnemann, D. and Neppolian, B. (2015) Nitrogen Doped Reduced Graphene Oxide Hybrid Metal Free Catalysts for Effective Reduction of 4-Nitrophenol. Science of Advanced Materials, 7, 1443-1449. https://doi.org/10.1166/sam.2015.2181

[17] Chen, T.-A., Wu, X. and Rieke, R.D. (1995) Regiocontrolled Synthesis of Poly(3-alkylthiophenes) Mediated by Rieke Zinc: Their Characterization and Solid-State Properties. Journal of the American Chemical Society, 117, 233-244. https://doi.org/10.1021/ja00106a027

[18] Chipara, M. and Chipara, M.D. (2008) Uv-Vis Investigations on Ion Beam Irradiated Polycarbonate. E-Polymers, Article No. 145. https://doi.org/10.1515/epoly.2008.8.1.1669

[19] Micocci, G., Serra, A., Tepore, A., Capone, S., Rella, R. and Siciliano, P. (1997) Properties of Vanadium Oxide Thin Films for Ethanol Sensor. Journal of Vacuum Science and Technology A, 15, 34-38. https://doi.org/10.1116/1.580471

[20] Gurunathan, S., Han, J.-W., Eppakayala, V. and Kim, J.-H. (2013) Green Synthesis of Graphene and Its Cytotoxic, Effects in Human Breast Cancer Cells. International Journal of Nanomedicine, 8, 1015-1027. https://doi.org/10.2147/IJN.S42047

[21] Takanezawa, K., Hirota, K., Wei, Q.-S., Tajima, K. and Hashimoto, K. (2007) Efficient Charge Collection with ZnO Nanorod Array in Hybrid Photovoltaic Devices. Journal of Physical Chemistry C, 111, 7218-7223. https://doi.org/10.1021/jp071418n

[22] De Freitas, J.N., Korala, L., Reynolds, L.X., Haque, S.A., Brock, S.L. and Nogueira, A.F. (2012) Connecting the (Quantum) Dots: Towards Hybrid Photovoltaic Devices Based on Chalcogenide Gels. Physical Chemistry Chemical Physics, 14, 15180-15184. https://doi.org/10.1039/c2cp42998e

[23] Yu, H., Li, Y., Dong, Y. and Huang, X. (2016) Fabrication and Optimization of Polymer Solar Cells Based on P3HT:PC70BM System. International Journal of Photoenergy, 2016, Article ID: 6725106.

[24] Holliday, S., Ashraf, R.S., Wadsworth, A., Baran, D., Yousaf, S.A., Nielsen, C.B., Tan, C.-H., Dimitrov, S.D., Shang, Z., Gasparini, N., Alamoudi, M., Laquai, F., Brabec, C.J., Salleo, A., Durrant, J.R. and McCulloch, I. (2016) High-Efficiency and Air-Stable P3HT-Based Polymer Solar Cells with a New Non-Fullerene Acceptor. Nature Communications, 7, Article No. 11585.

https://doi.org/10.1038/ncomms11585 